\title{
Mutation of Herpesvirus Saimiri ORF51 Glycoprotein Specifically Targets Infectivity to Hepatocellular Carcinoma Cell Lines
}

\author{
Susan J. Turrell ${ }^{1}$ and Adrian Whitehouse ${ }^{1,2}$ \\ ${ }^{1}$ Institute of Molecular and Cellular Biology, Faculty of Biological Sciences, University of Leeds, Leeds LS2 9JT, UK \\ ${ }^{2}$ Astbury Centre for Structural Molecular Biology, University of Leeds, Leeds LS2 9JT, UK
}

Correspondence should be addressed to Adrian Whitehouse, a.whitehouse@leeds.ac.uk

Received 18 June 2010; Revised 14 October 2010; Accepted 14 October 2010

Academic Editor: Michael J. Spinella

Copyright (C) 2011 S. J. Turrell and A. Whitehouse. This is an open access article distributed under the Creative Commons Attribution License, which permits unrestricted use, distribution, and reproduction in any medium, provided the original work is properly cited.

\begin{abstract}
Herpesvirus saimiri (HVS) is a gamma herpesvirus with several properties that make it an amenable gene therapy vector; namely its large packaging capacity, its ability to persist as a nonintegrated episome, and its ability to infect numerous human cell types. We used RecA-mediated recombination to develop an HVS vector with a mutated virion protein. The heparan sulphate-binding region of HVS ORF51 was substituted for a peptide sequence which interacts with somatostatin receptors (SSTRs), overexpressed on hepatocellular carcinoma (HCC) cells. HVS mORF51 showed reduced infectivity in non-HCC human cell lines compared to wildtype virus. Strikingly, HVS mORF51 retained its ability to infect HCC cell lines efficiently. However, neutralisation assays suggest that HVS mORF51 has no enhanced binding to SSTRs. Therefore, mutation of the ORF51 glycoprotein has specifically targeted HVS to HCC cell lines by reducing the infectivity of other cell types; however, the mechanism for this targeting is unknown.
\end{abstract}

\section{Introduction}

Herpesviruses are large double-stranded DNA viruses with genomes of between 100 and $250 \mathrm{~kb}$. They are divided into alpha, beta, and gamma subgroups depending on their genetic and biological properties [1]. The best characterised herpesvirus, Herpes simplex virus (HSV), is also the most developed gene therapy vector of this family, with several recombinant viruses involved in clinical trials [2-4]. However, the disadvantage of vectors based on alphaherpesvirinae, such as HSV, is their inability to persist in a dividing cell population. The use of gamma-herpesvirus vectors is an alternative approach. These viruses have many of the advantages of alphaherpesvirinae but are also able to transfer their genome to both daughter cells upon mitosis, thereby persisting in proliferating cells. We are currently developing gene therapy vectors based on Herpesvirus saimiri (HVS) [5-7]. HVS is the prototype gamma-2 herpesvirus [8] and was originally isolated from mononuclear blood cells of squirrel monkeys, where it causes an asymptomatic persistent infection [9]. It also infects other New World primates causing acute malignant T-cell lymphomas [10].

HVS is an attractive candidate for a gene therapy vector as, in addition to its persistence in dividing cell populations, its large genome can accept heterologous DNA of up to $150 \mathrm{~kb}$. HVS-based vectors also have no effect on cell growth [11] and are capable of latently infecting a wide range of cells in vitro and in vivo [12]. HVS exists as a stable episome in infected cells, greatly reducing its potential to disrupt genes and regulatory DNA sequences by recombination with genomic DNA. HVS strains used in gene therapy development are rendered nontransforming by the removal of the oncogenic sequences Stp and Tip [6].

Genetic engineering of HVS is difficult due to its sizeable genome. Originally HVS recombinant viruses were produced by cotransfecting a linearised plasmid, containing the gene of interest along with HVS homologous sequences, into permissive owl monkey kidney (OMK) cells along with the HVS genome [13, 14]. This technique, although successful was time consuming and required replication-competent 
viruses. Another strategy was the use of an overlapping cosmid library containing the genome of the HVS C488 strain $[15,16]$. This system was quicker than the homologous recombination method above; however, the transfection of multiple cosmid constructs into the OMK cells has a low efficiency.

Manipulation of HVS DNA has become easier and quicker with the advent of F-factor-based bacterial artificial chromosomes (BACs). BACs can be maintained in Escherichia coli as a single copy number construct and can stably maintain DNA fragments up to $300 \mathrm{~kb}$ in length [17]. The first HVS BAC produced had the BAC elements inserted into the H-DNA (the high $\mathrm{G}+\mathrm{C}$ content terminal repeat region that flanks the L-DNA coding region) of the viral genome [18]. However, this BAC was unable to establish a latent infection as the H-DNA is required for tethering of the HVS genome to host chromosomes during cell division [19-23]. Therefore, a second HVS BAC was produced by our lab with the BAC element inserted into ORF15 [24]. This ORF was chosen as it encodes a nonessential gene that expresses a viral homolog of CD59, a complement control protein. This HVS BAC contains the F-factor-derived elements essential for growth in E. coli, along with cassettes for hygromycin and chloramphenicol resistance, a GFP reporter gene controlled by the CMV promoter and a unique rare restriction site, I-PpoI, to allow conventional cloning of transgenes into the BAC. This HVS BAC is a valuable tool for creating recombinant viruses to develop for gene therapy applications.

One feature of HVS that makes it amenable to gene therapy vector development is its broad cell tropism. HVS has been shown to infect several human haematopoietic cell lines $[6,14,16]$. Moreover, the virus has been used to infect totipotent mouse ES cells, and GFP transgene expression was maintained throughout differentiation of those cells into mature haematopoietic cells [25]. HVS also has potential as a cancer gene therapy vector. The vector can efficiently infect a number of carcinoma cell lines [26, 27], and studies have shown that it can efficiently penetrate three-dimensional spheroid cell cultures similar to tumours in vitro and can persist as a stable episome in tumour xenografts after direct intratumoral injections in vivo [28]. A separate in vivo study has shown that HVS-GFP-infected tumour xenografts had sustained transgene expression over 3 months in various organs without any spread of the vector [11].

Although a wide tropism is suitable in some applications, a more targeted approach is preferable to increase vector uptake in diseased cell types. One way to establish a more cell-selective infection is to retarget the virus by altering how it enters cells. Hepesvirus cell entry is a multi-step process mediated by interactions between several glycoproteins at the virion surface and cognate receptors expressed at the cell membrane. Virus binding is followed by membrane fusion (the viral envelope either fuses with the membrane at the cell surface or within an endosome), allowing the viral capsid to enter the cytoplasm, where it is transported to the nuclear periphery. Here, the capsid is degraded and the viral DNA enters the nucleus via the nuclear pore.
Little is known about the mechanisms of HVS cell entry. Initial binding is thought to be mediated via an interaction between the viral glycoprotein ORF51 and cellular glycosaminoglycans (GAGs), such as heparan sulphate [29]. This is suggested to enable further specific interactions between other viral glycoproteins such as $\mathrm{gB}$ and $\mathrm{gH} / \mathrm{gL}$ with as yet unknown receptors, facilitating membrane fusion and viral entry.

HVS ORF51 is not well studied but has a homolog in Kaposi's Sarcoma-associated Herpesvirus (KSHV), glycoprotein K8.1. There is some ambiguity as to the extent that K8.1 affects cell entry, as it has been shown that blocking this receptor inhibits entry whereas other observations see no apparent effect [30, 31]. A research article by Means [29] investigated the function of HVS ORF51 and showed that the protein contains a putative heparin-binding domain. Moreover, ORF51 was shown to bind to heparin-conjugated beads, and HVS infectivity could be neutralised by incubation with soluble heparin. ORF51 is therefore an ideal candidate to mutate for cellular retargeting, as it does not appear to be intrinsically involved in fusion of the cell membrane and viral envelope. Disruption of the gene will not adversely affect cell-virus fusion, but a gain of function mutation may cause an alteration to the viral tropism.

Although in a natural infection, HVS is found in T-lymphocytes, when administered intravenously in mice several organs are latently infected with HVS. Transgene expression was mainly localised to the liver, with expression also detected in the spleen, lung, and kidneys [32]. This suggests that this vector is suited to gene therapy of liver diseases. We therefore set out to enhance this natural tropism by targeting HVS to neoplastic liver cells.

Hepatocellular carcinoma (HCC) is the 5th most common cancer worldwide [33] and is caused by sustained liver damage, for example, from chronic hepatic infection or alcohol abuse [34, 35]. One feature of this cancer that could be exploited for gene therapy applications is the overexpression of somatostatin receptors (SSTRs) on the surface of HCC cells [36]. Somatostatin or its analogues octreotide and vapreotide have been used in the treatment of HCC and other cancers; however, their effectiveness has been subject to debate $[37,38]$. It has been shown that all 5 types of SSTR are present on the majority of HCCs [36]. Therefore a gene therapy vector that effectively binds to SSTRs could be a valuable tool against hepatocellular carcinoma. We have previously demonstrated that HVS naturally displays a tropism for the liver when administered intravenously in mice [32]. However, it may be possible to further increase this targeting to preferentially infect cancerous liver tissue by incorporating SSTR-binding properties in HVS-based vectors.

We have therefore produced a recombinant virus, HVS mORF51, by RecA-mediated recombination. The HVS mORF51 virus was constructed, so that the heparan sulphate-binding region of HVS ORF51 was substituted for an SSTR binding motif. This mutation was designed to alter the tropism of the glycoprotein, so that it preferentially binds SSTRs, thus increasing the affinity of the mutant virus for HCC cells. 


\section{Materials and Methods}

2.1. HVS Propagation and Cell Culture. HVS-GFP-BAC is based on the A11 S4 strain as described previously [24]. To produce working stocks of HVS mORF51, the virus was propagated in the permissive owl monkey kidney (OMK) cell line. Viral DNA was transfected into OMK cells in 6 well plates with Lipofectamine 2000 (Invitrogen). Cells were exposed to the lipid-DNA complexes for $4-6 \mathrm{~h}$ in serumfree DMEM. The media was then exchanged for 5\% DMEM to allow viral infection. This virus-containing media was then used to reinfect large quantities of OMKs to produce sufficient amounts of working virus stocks, as previously described. All human cancer cell lines, HEK 293T and OMK cells, were grown and passaged in DMEM with 10\% foetal bovine serum and 5 units/ml penicillin/streptomycin. Virus propagation was performed in 5\% DMEM with pen/strep.

2.2. Constructs. pKOV Kan $\Delta \mathrm{Cm}$ is modified from the pKOV vector described previously [39]. The mutant HVS ORF51 gene was constructed in pCR blunt (Invitrogen). The mutated region of ORF51 (plus homology regions) consisted of nucleotides 72626-73264 of the HVS genome followed by insert sequence AGA TCT CCC ACC GGT GCG TGT CGG TTT TGG AAA ACT TGG TGT GCG AGA TCT and nucleotides 73310-73810. This "mORF51" sequence was then inserted into pKOV Kan $\Delta \mathrm{Cm}$ via NotI/PstI restriction and ligation. pDF25-Tet is based on the pDF25 vector with the $\mathrm{Cm}^{\mathrm{R}}$ gene replaced with a gene conferring tetracycline resistance. This substitution prevented recombination with the HVS-GFP-BAC (which contains a $\mathrm{Cm}^{\mathrm{R}}$ gene) as previously described.

2.3. RecA-Mediated Recombination. DH10 $\beta$ E. coli cells harbouring the HVS-GFP-BAC episome were made competent with $\mathrm{RbCl}$. Cells were cotransformed with $5 \mu \mathrm{g}$ pDF-Tet and $1 \mu \mathrm{g}$ pKOV Kan mORF51 and then plated onto LB agar containing chloramphenicol $(\mathrm{Cm})$, kanamycin (Kan) and tetracycline (Tet) at $30^{\circ} \mathrm{C}$ overnight. Positive colonies were picked into $1 \mathrm{ml} \mathrm{LB}$, and immediately $200 \mu \mathrm{l}$ was plated onto LB agar plates containing chloramphenicol and kanamycin. These were incubated at $43^{\circ} \mathrm{C}$ overnight to select for cointegrants. The larger colonies that grew were then analysed by restriction analysis and subsequent pulse field gel electrophoresis.

E. coli containing the cointegrant HVS DNA were made competent as above (but grown at $43^{\circ} \mathrm{C}$ with $\mathrm{Cm}$ and Kan). The cells were transformed with $50 \mathrm{ng}$ pDF25-Tet and grown overnight at $30^{\circ} \mathrm{C}$ on $\mathrm{LB}$ agar containing $\mathrm{Cm}$ and Tet. Colonies were subsequently picked into $1 \mathrm{ml} \mathrm{LB}$ containing $5 \%$ sucrose $(\mathrm{Cm}+\mathrm{Tet})$ and incubated at $30^{\circ} \mathrm{C}$. After $4 \mathrm{~h} 100 \mu \mathrm{l}$ of this culture was transferred to $1 \mathrm{ml}$ fresh LB with the same selection and again incubated for $4 \mathrm{~h}$ at $30^{\circ} \mathrm{C}$. This was repeated again and the $1 \mathrm{ml}$ culture left at $30^{\circ} \mathrm{C}$ overnight. The overnight culture was streaked onto $\mathrm{Cm}$ plates containing $5 \%$ sucrose and incubated at $43^{\circ} \mathrm{C}$. These colonies were then replica plated onto agar with $\mathrm{Cm}+\mathrm{Kan}$, and $\mathrm{Cm}$ only plates to screen for colonies with a mutation in the SacB gene of pKOV Kan mORF51. Those colonies that did not grow on the Kan plates were analysed further by PCR, restriction analysis, and DNA sequencing.

2.4. Pulse Field Gel Electrophoresis. 1.2\% agarose gels were made with pulse field electrophoresis grade agarose (Sigma) and $0.5 \mathrm{x}$ TBE buffer. $10 \mu \mathrm{l}$ of DNA loading buffer was mixed with DNA samples prior to loading. Midrange I PFG Marker (New England BioLabs) or PFG Marker II (New England BioLabs) was used along with Lambda DNA HindIII Digest (New England BioLabs) to compare sizes of DNA fragments. The BioRad CHEF-DR II control module was set at 6 volts for $11.5-16.0 \mathrm{~h}$ depending on the size of expected fragements. The $0.5 \mathrm{x}$ TBE buffer in the electrophoresis cell tank was cooled using a Bio-Rad Model 1000 Minichiller set to $15.5^{\circ} \mathrm{C}$. Gels were stained using $200 \mathrm{ml}$ of $0.1 \mu \mathrm{g} / \mathrm{ml}$ ethidium bromide (Sigma) in $0.5 x$ TBE buffer subsequent to running.

2.5. Neutralisation Assays and Flow Cytometry. All infections were carried out in 6 well plates with media containing 5\% FBS. Neutralisation agents (heparin (Sigma), somatostatin (Calbiochem) and SSTR Ab (Diagnostic Biosystems)) were added to the media at the appropriate concentrations, $1 \mathrm{~h}$ prior to the addition of virus and incubated at $37^{\circ} \mathrm{C}$. HVSinfected cells were prepared for FACS analysis 48 hours after infection. $5 \times 10^{6}$ cells were trypsinised and resuspended in PBS. Data was collected with a BD Facscalibur flow cytometer and data was analysed using Cellquest software.

\section{Results}

3.1. RecA-Mediated Recombination of HVS ORF51. By analysing the amino acid sequence of ORF51, Means [29] identified motifs which could encode some of the structural features of the protein, including a putative heparan sulphate-binding sequence, comprising residues 214-228. Figure 1 outlines the alteration made to the ORF51 sequence by replacing amino acids 214-228 (peptide sequence SKHTNKLKPFKHKLQ) with a sequence determined by phage library selection to have a nanomolar affinity for all 5 SSTRs (CRFWKTWC) [40]. This peptide contains a disulphide bridge between the flanking cysteine residues which is essential for ligand binding. Restriction endonuclease sites were also added in order to clone the this peptide sequence into a vector prior to RecA mediated recombination; BglII at either end of the sequence to allow insertion into the gene, and AgeI as an analytical tool (AgeI cuts infrequently in the HVS genome, so this added restriction site could be used for identifying positive clones). Alanines were used between the SSTR binding sequence and the restriction sites to exchange a similar number of residues with the original sequence. The final peptide sequence that replaced the heparan sulphatebinding motif is therefore RSPTGACRFWKTWCKRS. The recombination method used, consisting of a cointegration step and a second step where mutant clones are resolved, is outlined in Figure 2. 


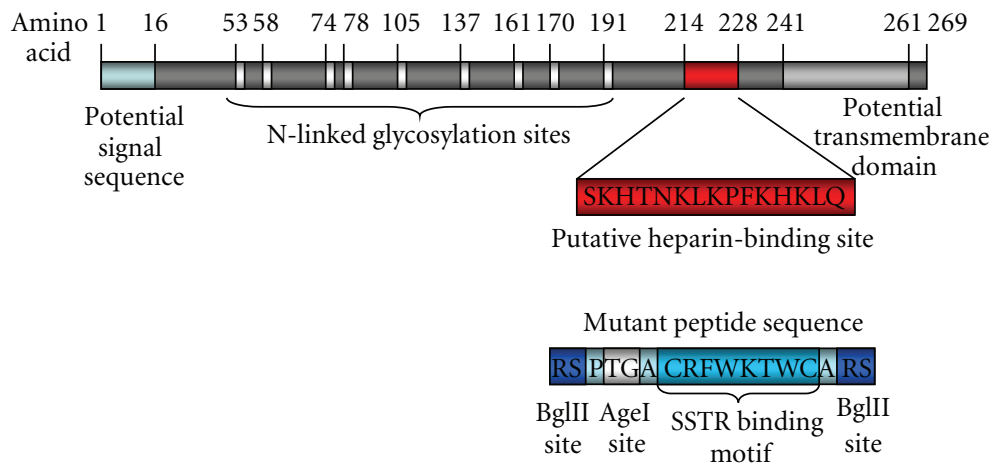

FIGURE 1: Substitution of the heparan sulphate-binding region of HVS ORF51 protein. Analysis of the peptide sequence of the 269 amino acid protein indicates that there is an $\mathrm{N}$-terminal signal sequence, $9 \mathrm{~N}$-linked glycosylation sites, a potential heparan sulphate-binding site and a transmembrane domain. In the mutant ORF51 virus the heparan sulphate-binding site, highlighted in red, is replaced with the peptide sequence in blue. This sequence contains the SSTR binding motif.

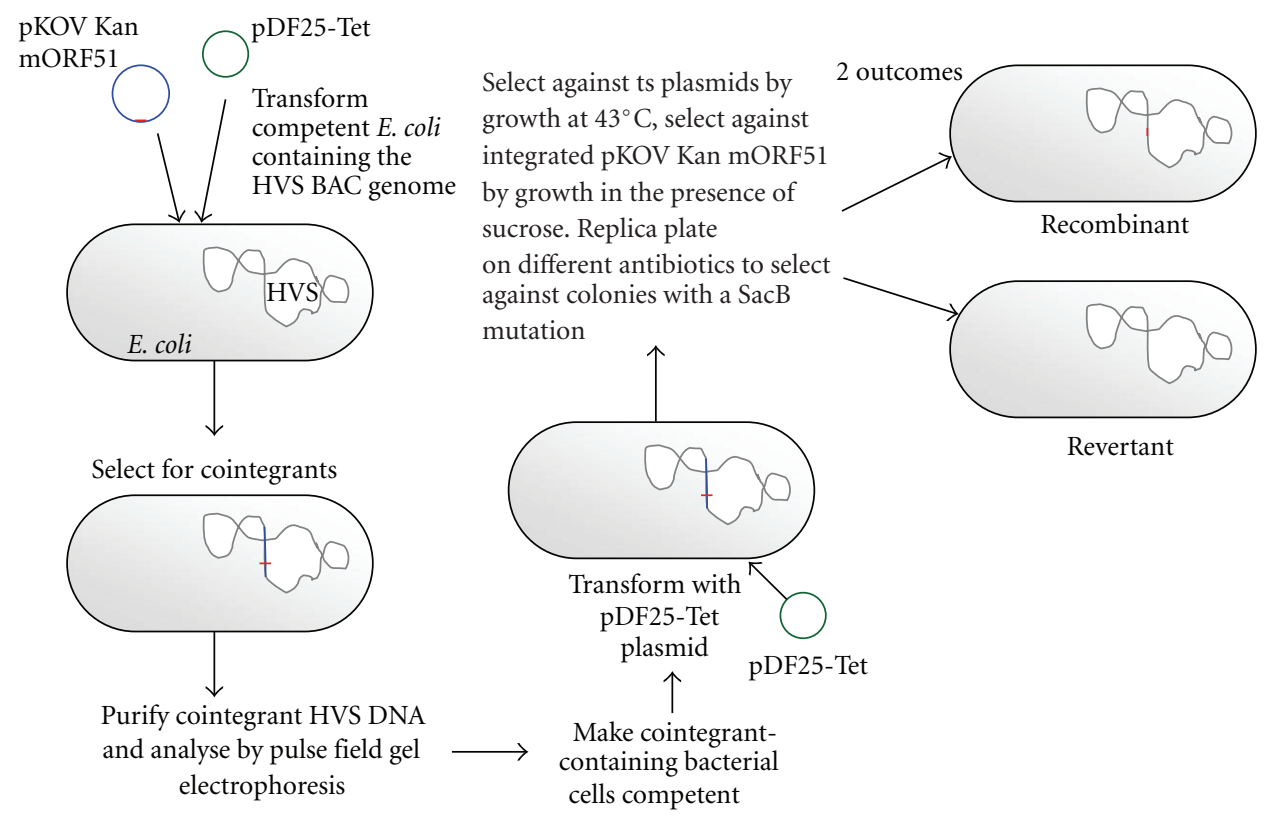

Figure 2: Schematic of the RecA-mediated recombination method used to develop HVS mORF51. Two plasmids are transformed into competent $E$. coli cells that already harbour the HVS-GFP-BAC genome. These plasmids are both temperature sensitive and have antibiotic resistance markers for ease of selection. The first plasmid, pDF25-Tet, contains a RecA expression cassette to facilitate recombination, as well as a tetracycline resistance gene. The second, pKOV Kan, contains the mutated region of the HVS genome flanked on either side by regions of homology of at least $500 \mathrm{bp}$. These homology regions target the recombination event to a specific point in the viral DNA. pKOV Kan also contains a SacB gene, allowing negative selection on sucrose-containing medium, and a kanamycin resistance gene. When both plasmids are transformed into the E. coli, RecA expressed from pDF25-Tet induces a recombination event between one of the homology regions in $\mathrm{pKOV}$ Kan and the corresponding region in the HVS genome. Clones containing the pKOV Kan plasmid integrated into the HVS genome are then selected and made competent. These cointegrant clones are then retransformed with pDF25-Tet in order to produce a second recombination event. Depending on whether this recombination is in the same or adjacent homology region to the initial recombination, a revertant clone or a recombinant clone will be formed. Selection is used to identify recombinants, which can then be further analysed and confirmed by restriction digest and sequencing.

Competent E. coli cells harbouring HVS-GFP-BAC episomal DNA were cotransformed with the pKOV Kan mORF51 integrating vector and the pDF25-Tet vector which expresses RecA. This promoted the insertion of pKOV Kan mORF51 into HVS-GFP-BAC via a recombination event at one of the two homology regions flanking mORF51. Depending on the site of recombination, the plasmid could be inserted in 2 different orientations (shown in Figure 3(b)). It is preferable to obtain cointegrants in both orientations as one may be more dynamically favourable for the subsequent recombination step (being more likely to produce a mutant clone rather than revertant, due to steric hindrance). Both orientations can be identified by AgeI restriction digest analysis of purified HVS DNA (Figure 3(a)). 


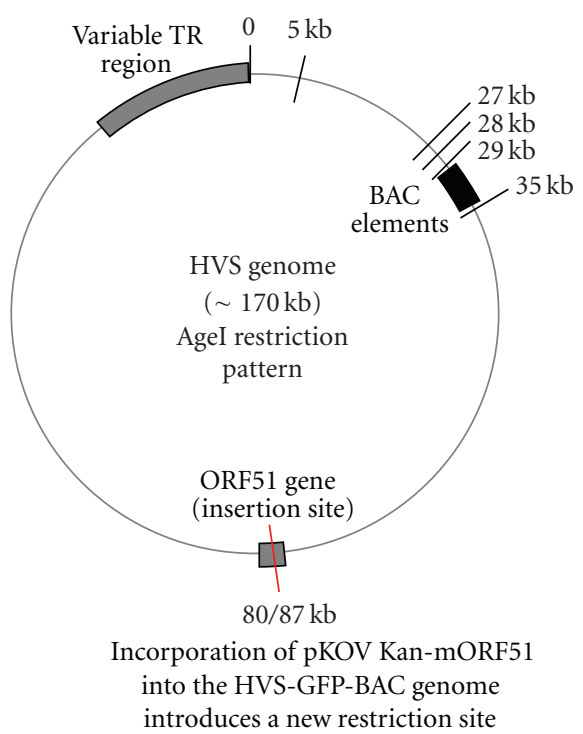

Expected bands from AgeI digest

\begin{tabular}{|c|c|}
\hline HVS & $\begin{array}{c}\text { HVS- } \\
\text { mORF51 }\end{array}$ \\
\hline $22 \mathrm{~kb}$ & $22 \mathrm{~kb}$ \\
\hline $1 \mathrm{~kb}(\mathrm{x} 2)$ & $1 \mathrm{~kb}(\mathrm{x} 2)$ \\
\hline $6 \mathrm{~kb}$ & $6 \mathrm{~kb}$ \\
\hline$\sim 130 \mathrm{~kb}$ & $45 / 52 \mathrm{~kb}$ \\
\hline & $\sim 80 \mathrm{~kb}$ \\
\hline
\end{tabular}

(a)
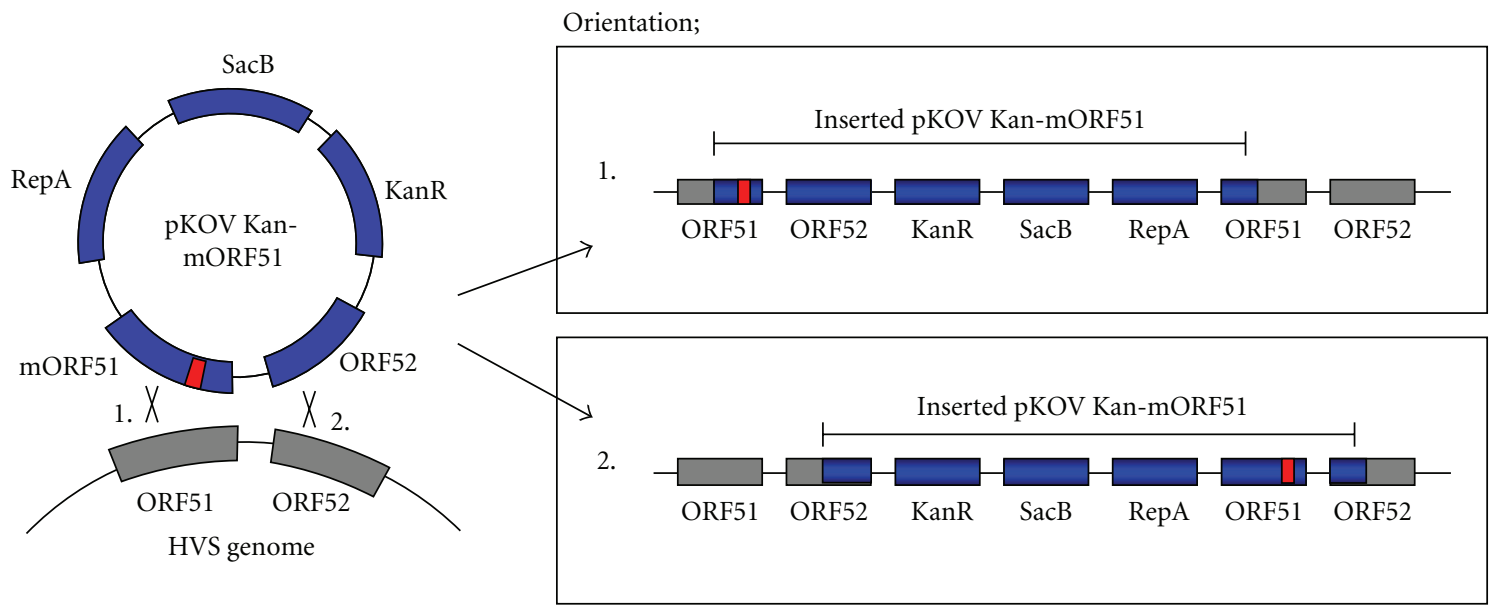

(b)

FIgUre 3: Possible orientations of pKOV Kan mORF51 cointegrants as seen by AgeI digest. (a) AgeI restriction map of the HVS genome. The restriction site marked in red is introduced when homologous recombination occurs between the pKOV Kan mORF51 plasmid and the complementary sequence in the viral genome. This introduced restriction site can then be used for identification of cointegrants. (b) Possible orientations of cointegrants. Depending on which homology region the reaction occurs (either $5^{\prime}$ or $3^{\prime}$ to the mutated ORF51 gene in pKOV Kan mORF51), cointegrants can be in one of two orientations. The mutated region containing the introduced AgeI site is shown in red. The pKOV Kan-mORF51 DNA is shown in blue, and the HVS DNA is shown in grey. The two orientations of cointegrant can be detected upon AgeI digestion analysis due to a $7 \mathrm{~kb}$ difference in the size of the $\sim 50 \mathrm{~kb}$ fragment (see table). The larger $\sim 80 \mathrm{~kb}$ fragment contains the terminal repeat (TR) region of the genome so is not suitable to detect this small difference as the number of TRs is not fixed.

12 possible cointegrant clones were investigated using AgeI restriction analysis and then separated on a pulse field electrophoresis gel. These were compared to the "wild-type" HVS-GFP-BAC. All 12 had a restriction pattern consistent with pKOV Kan mORF51 insertion. Figure 4 shows four of these clones 3,4,8, and 9 with the HVS-GFP-BAC digest. As predicted, the $130 \mathrm{~kb}$ band present in the HVSGFP-BAC lane has been digested into two smaller bands in the cointegrant clones, indicating that pKOV Kan mORF51 has successfully inserted into the genome at the correct location. These clones also clearly show the two different expected restriction patterns consistent with both possible orientations of pKOV Kan mORF51. Clones 3 and 4 have the pKOV Kan mORF51 vector in orientation 1, whereas clones 8 and 9 are in orientation 2 (as predicted in Figure 3). Interestingly, the largest fragments in clones 8 and 9 are different sizes due to the variable terminal repeat region in the H-DNA of the genome. After sequence analysis to assess for any unwanted mutation, these four clones were used for further recombination.

Clones 3, 4, 8, and 9 were made chemically competent and then transformed with pDF25-Tet to induce a second recombination event. This could result in either a revertant or a mutant clone as shown in Figure 5. After the appropriate 


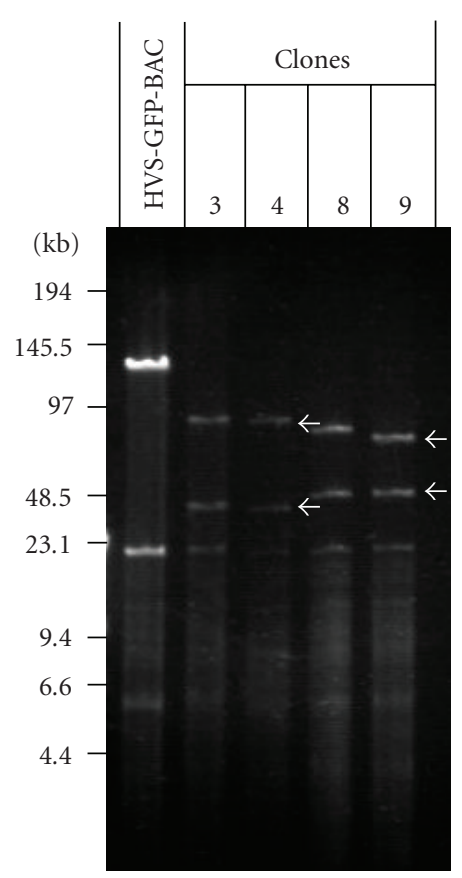

Figure 4: AgeI restriction analysis of cointegrants formed by homologous recombination. The mutated version of the ORF51 gene contains an AgeI restriction site. This extra restriction site can be used as a marker for the integration of the pKOV Kan mORF51 vector into the HVS genome. Pulse field gel electrophoresis of possible cointegrant clones 3, 4, 8, and 9 reveals successful integration, as the $\sim 130 \mathrm{~kb}$ band seen in HVS-GFP-BAC is cleaved into 2 smaller bands (indicated by arrows) due to the introduced restriction site. The 2 different orientations of pKOV Kan mORF51 can be visualised as clones 3 and 4 show a restriction pattern with bands at $45 \mathrm{~kb}$ and $\sim 90 \mathrm{~kb}$, whereas clones 8 and 9 have bands at $52 \mathrm{~kb}$ and $\sim 85 \mathrm{~kb}$. This $7 \mathrm{~kb}$ difference in the restriction site corresponds to the length of pKOV Kan mORF51.

selection, BAC DNA from resulting clones was purified by miniprep, digested with AgeI, and analysed by pulse field electrophoresis. Colonies were formed after recombination of cointegrants 3 and 9. Figure 6(a) shows the restriction analysis of 6 colonies from each of these cointegrants (representative of 12 screened). HVS-GFP-BAC was also digested as a negative control. All of the colonies originating from cointegrant 3 have reverted back to "wild type," showing the same restriction pattern as the HVS-GFP-BAC lane. The loss of the AgeI restriction site at $\sim 80 \mathrm{~kb}$ on the restriction map (Figure 3 ) restores the $\sim 130 \mathrm{~kb}$ band seen with "wild-type" viral DNA. Clones 9A, 9B, and 9F are also revertants. The restriction pattern of $9 \mathrm{C}$ is not consistent with either a revertant or mutant genotype, with a band at approximately $95 \mathrm{~kb}$. This may have been due to the genome undergoing a deletion. 9E seems to have a dual population of genomes, some of which have reverted and some of which have retained the mutant copy of the gene. However, 9D shows the correct restriction pattern and therefore has the pKOV Kan plasmid removed while retaining the mutation.

As seen in Figure 6(b), the revertant restriction pattern is identical to the "wild type," however, the bands for the mutant clone 9D are slightly different in size to its parental cointegrant 9. This is due to the removal of the $7 \mathrm{~kb}$ plasmid, shortening the $52 \mathrm{~kb}$ band seen with cointegrant 9 to $45 \mathrm{~kb}$. Sequence analysis confirmed the presence of the mutant gene in the HVS mORF51 genome, and working stocks of the recombinant virus were then produced by transfection into permissive OMK cells.

\subsection{Mutation of HVS ORF51 Affects Infectivity in Several} Human Cancer Cell Lines. To investigate the effects of mutating ORF51, a panel of cell lines were infected with HVS-GFP-BAC or HVS mORF51, and the infection rate for each cell line was compared. Due to potential changes in vector tropism, infectivity was compared by analysing dosedependent rates of infection using increasing viral titres. The resulting fluorescence was measured as an indication of the level of infection using flow cytometry. Examples of the raw dot plots obtained when infecting permissive OMK cells with HVS-GFP-BAC are shown in Figure 7(c). Data confirm previous experiments in our laboratory showing that HVS-GFP-BAC can infect a wide range of human cancer cell lines $[6,28]$. Figure 7 (a) shows the percentage of HVSGFP-BAC infected cells (measured by GFP expression) in a range of human cell lines, including lung, colon, and liver. Also shown is infection in the fully permissive OMK cell line as a positive control. HVS-GFP-BAC has a high tropism for the Huh7 and 7.5 cell lines, with an m.o.i of 2 infecting nearly $100 \%$ of cells. The HepG2 liver cancer cell line is less efficiently infected, with the same titre infecting only $35 \%$ of the cells. Interestingly the infection rate in HCC cell lines is higher than that observed in lung, colorectal, and the human embryonic kidney cell line. As expected, the OMK cells are relatively well infected.

When an equivalent titre of HVS mORF51 virus was used to infect the same cell lines, a distinct infection profile is observed (Figure 7(b)). All three HCC cell lines have similar infection rates to those previously observed with the "wildtype" HVS-GFP-BAC virus, for example, 30\% of HepG2 cells are infected compared to a $35 \%$ infection with HVSGFP-BAC. However, the level of infection for all the other cell types decreased dramatically. This effect appears most prominent with the OMK cell line, where HVS-GFP-BAC at an m.o.i of 2 results in an $80 \%$ infection rate as measured by fluorescence, whereas the same titre of HVS mORF51 infected on average $17 \%$ of cells.

This pattern can be more clearly observed in Figure 8. Here, the HVS mORF51 infection (using an m.o.i of 2) is displayed as a ratio of the infection seen with the equivalent titre of HVS-GFP-BAC. This removes the variability of viral tropism and allows a more relevant comparison of different cell types. Where HVS mORF51 can infect HCC cell lines to a similar extent to HVS-GFP-BAC (over 80\%), infection levels of the mutant virus in A549 lung carcinoma cell line, OMK, and HEK 293T are all reduced to only $~ 20 \%$ of "wildtype" infection. The SW480 infection is most attenuated by the mutation, retaining only $4 \%$ of "wild-type" infection. These results suggest that mutation of the ORF51 protein affects viral entry in certain cell types. The mutation in 


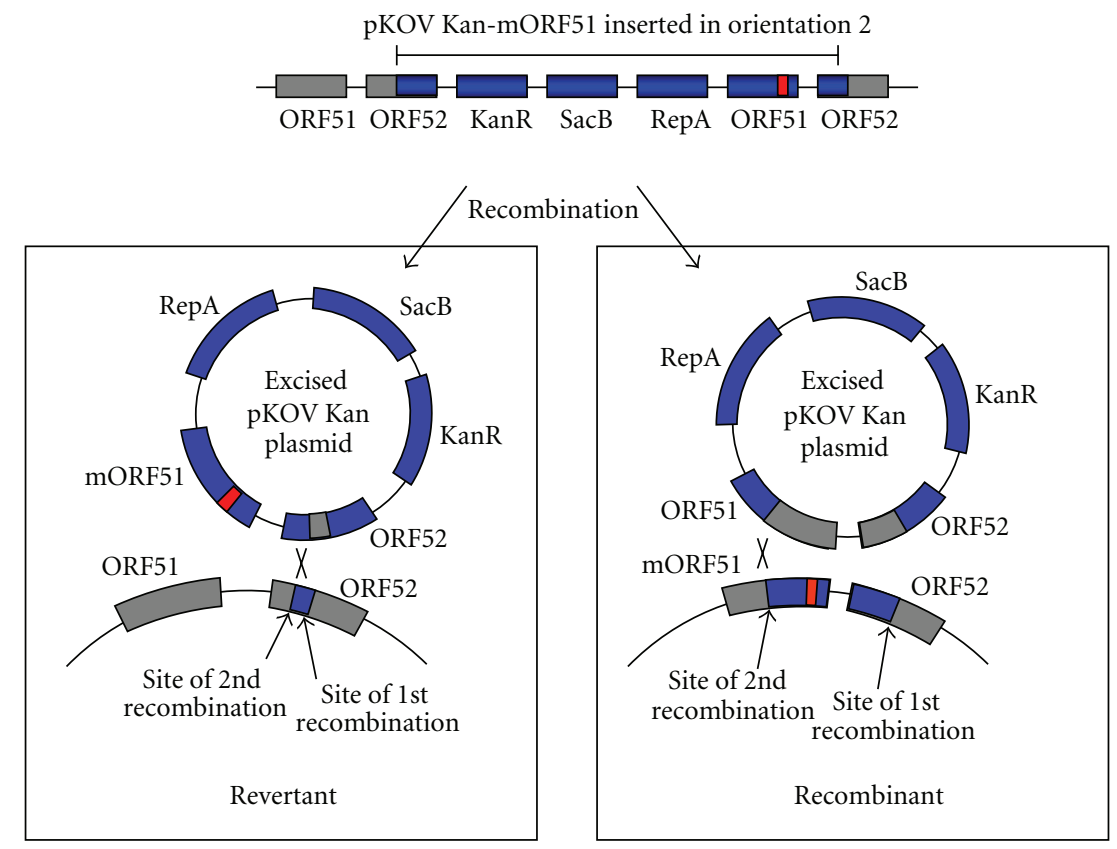

FIGURE 5: Schematic describing the resolution of cointegrant clones. Cointegrants which have the pKOV Kan-mORF51 plasmid (shown in blue) inserted into the HVS genome (shown in grey) undergo a second recombination event, resulting in two possible outcomes. If the recombination site is in the same homology region as the first recombination, the intact pKOV Kan mORF51 plasmid is excised, forming a revertant. However, if this recombination occurs in the opposite homology region to the previous recombination event, the mutated region (shown in red) remains in the HVS genome, while the wild-type ORF51 is incorporated into the pKOV Kan plasmid.

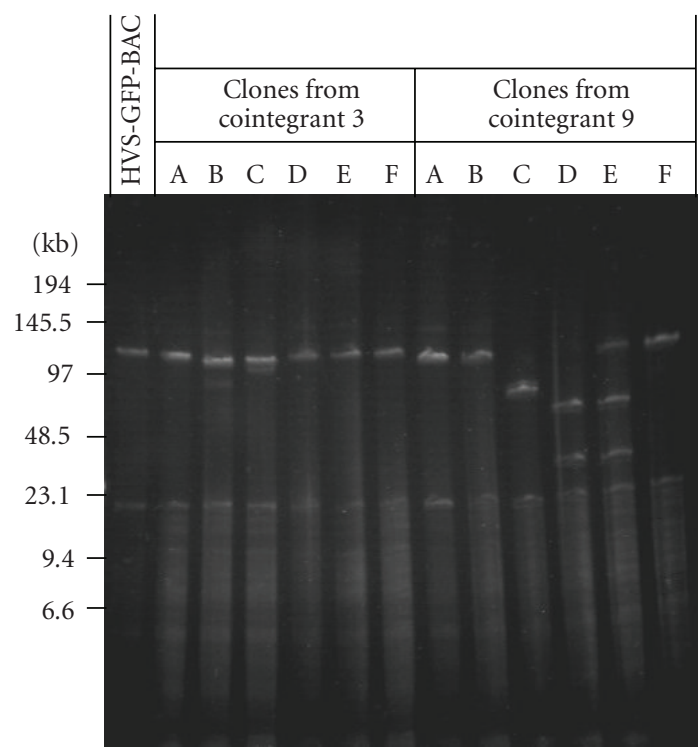

(a)

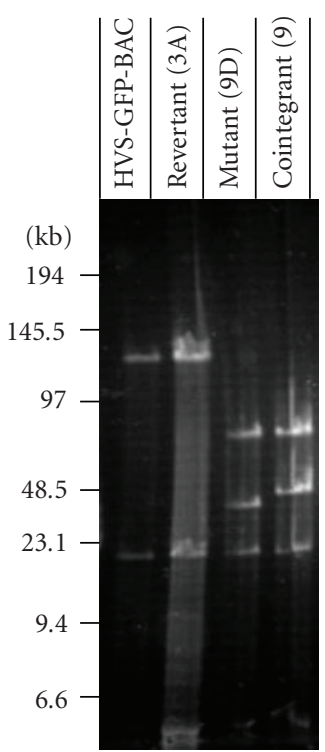

(b)

Figure 6: AgeI restriction analysis of clones derived from cointegrants during homologous recombination. (a) Cointegrants formed from the first stage of RecA-mediated recombination underwent a second recombination event to remove the integrated pKOV Kan plasmid. This second recombination event could result in either a revertant or a mutant genotype. Of the 12 colonies screened, clone 9D had the desired restriction pattern consistent with a mutated ORF51 gene. (b) The mutant clone 9D was digested and run alongside a revertant 3A and the cointegrant clone 9 from which it originated. The loss of the integrated pKOV Kan plasmid can be visualised by the $52 \mathrm{~kb}$ band in the final lane decreasing in size by $7 \mathrm{~kb}$ to $45 \mathrm{~kb}$. 


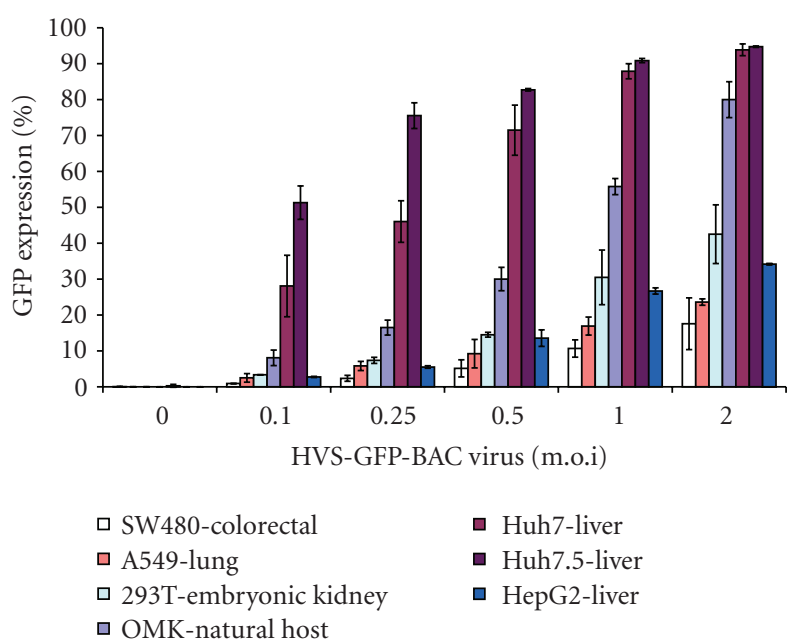

(a)
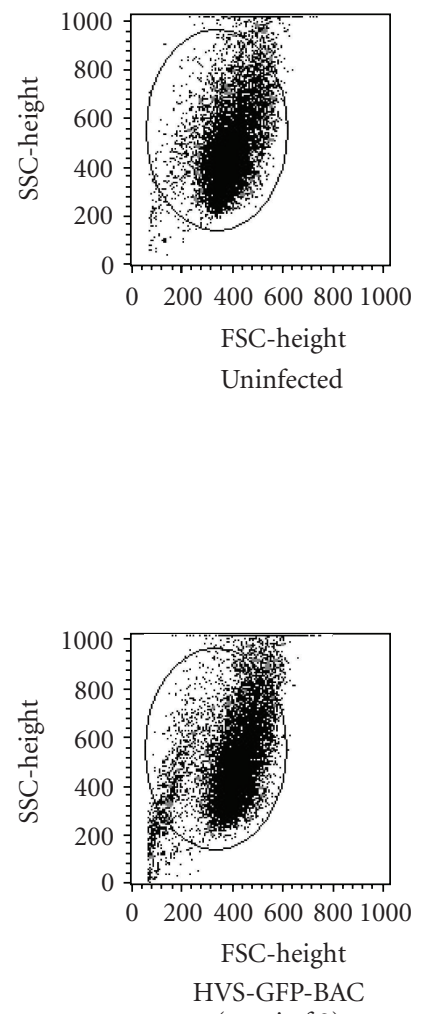

(m.o.i of 2)

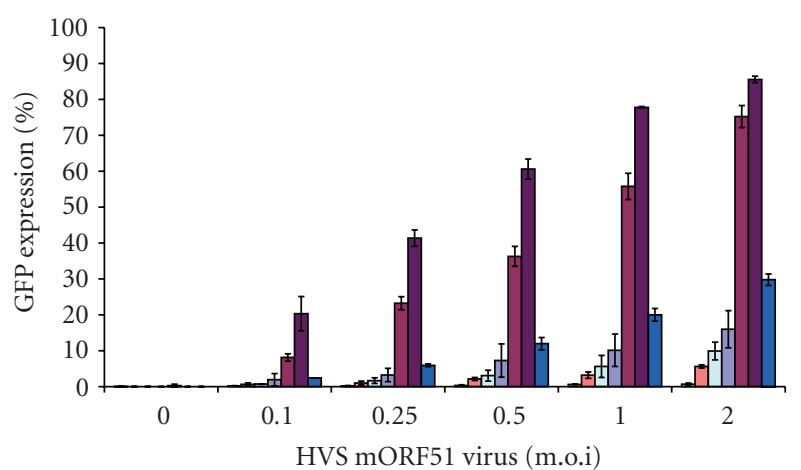

口 SW480-colorectal

๑ A549-lung

口 293T-embryonic kidney

口 OMK-natural host
Huh7-liver

- Huh7.5-liver

- HepG2-liver

(b)
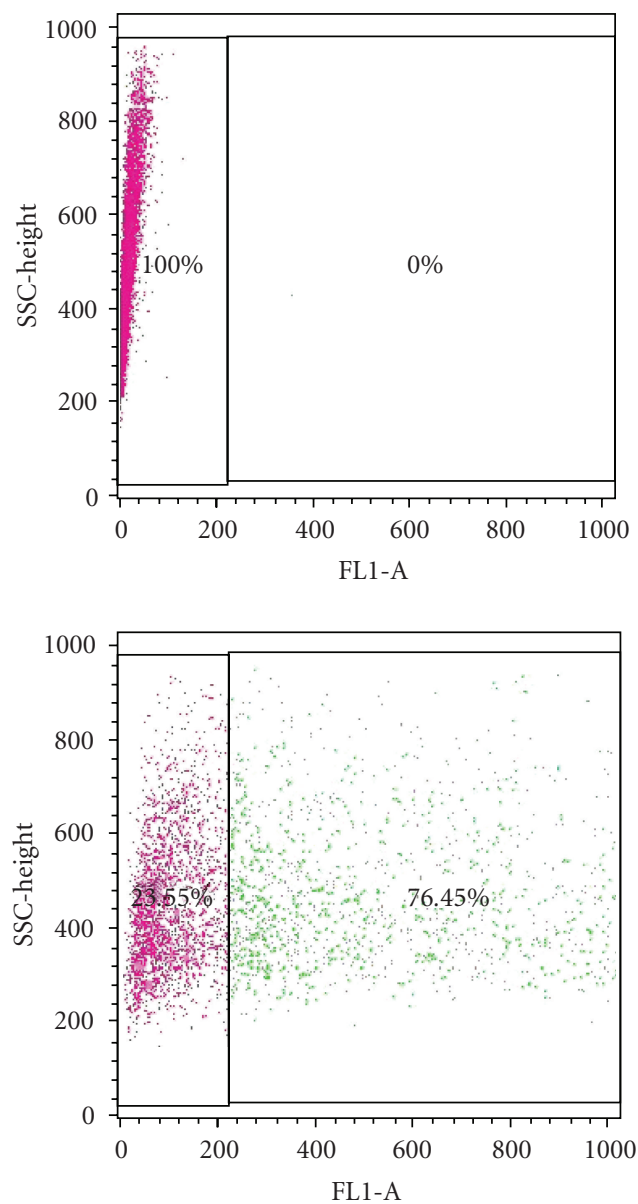

(c)

FIGURE 7: Comparison of wild-type and mutant virus entry measured by GFP expression. A range of human cancer cell lines were infected with increasing amounts of HVS-GFP-BAC (a), and HVS mORF51 (b). Owl monkey kidney (OMK) cells (permissive to the virus) were also used as a control, representative dot plots of which are shown in (c). $48 \mathrm{~h}$ after infection, GFP expression was measured by flow cytometry using a Becton Dickinson FacsCalibur $(n=2)$. Mutation of the ORF51 glycoprotein inhibits virus entry in OMK cells and several of the cancer cell lines. However, the HCC-derived cell lines are still able to be efficiently infected, suggesting that the SSTR binding region in the mutated protein facilitates viral attachement in these SSTR-expressing cells. 


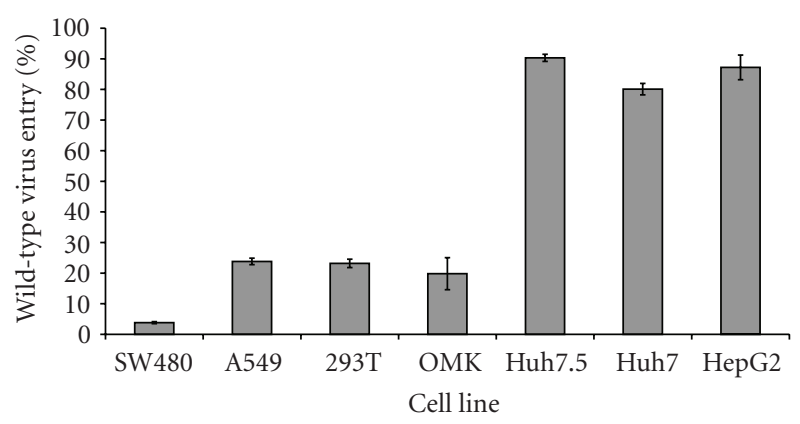

Figure 8: HVS mORF51 infection rates shown as a percentage of HVS-GFP-BAC infection in different cell types. Each virus, at an m.o.i of 2, was used to infect a panel of cell lines. GFP fluorescence (used as a marker of infected cells) was measured by flow cytometry $48 \mathrm{~h}$ after infection $(n=2)$. All hepatocellular carcinoma cell lines (Huh7, Huh7.5, and HepG2) have an infection rate of over $80 \%$ of that observed with HVS-GFP-BAC. In the permissive OMK cell line, as well as in the A549 lung cell line and HEK 293T cells, HVS mORF51 infects only approximately $20 \%$ of the number of cells infected with HVS-GFP-BAC. HVS mORF51 infects colorectal cancer cell line SW480 most inefficiently, producing an infection rate just of $4 \%$ compared to HVS-GFP-BAC.

HVS mORF51 is designed to ablate the heparan sulphatebinding role of the protein, and this loss of function may be responsible for the decreased infection rates. Alternatively, the insertion of the SSTR binding motif may have provided a gain of function to the protein, allowing higher rates of infection specifically in the HCC cell lines.

\subsection{HVS mORF51 Infection Is Independent of SSTR1 Expres-} sion. Somatostatin is a repressor of gastrointestinal hormone production and also inhibits the release of insulin and glucagon from the pancreas [41, 42]. Therefore, somatostatin receptors are present in healthy pancreatic tissue. It has been documented that during the development of pancreatic cancer the expression of these SSTRs is lost [43]. Consequently, pancreatic cancer cell lines would provide a suitable negative control cell for HVS mORF51. We compared HVS mORF51 infection between these cells and pancreatic cancer cell lines stably transfected with a construct expressing SSTR1 [43]. Figure 9 shows the infection levels observed, measured by GFP expression. In both cell lines, there was no increased infectivity in the SSTR1-positive cells. Surprisingly, the infection rate was slightly higher in the SSTR1 negative cells. This result indicates that the high levels of infection observed in the HCC cell lines may not be due to the presence of SSTR1 on the cell membrane. However, there are 5 types of SSTR, and although the SSTR binding motif used in the HVS mORF51 mutation should bind all 5 of these Gprotein coupled receptors, it may have higher affinities for certain receptors than others, especially if it is in a restricted conformation.

3.4. Soluble Heparin Inhibits HVS-GFP-BAC Entry to a Greater Extent Than HVS mORF51. The natural cellular ligand of ORF51 is purported to be heparan sulphate-containing proteoglycans present on the surface of cells.Means [29] demonstrated that ORF51 binds heparin and that soluble heparin inhibits HVS infection of OMK cells. To confirm these results, this experiment was repeated using a flow cytometry assay measuring GFP-expression as an indicator of viral infection. Soluble heparin was incubated with cells for $1 \mathrm{~h}$ at $37^{\circ} \mathrm{C}$ prior to the addition of HVSGFP-BAC or HVS mORF51. The heparin neutralisation curve for HVS-GFP-BAC is shown in Figure 10. Results demonstrate that as the concentration of soluble heparin was increased from 0.01 to $1 \mathrm{mg} / \mathrm{ml}$ an initial slight increase in viral infection was observed as previously reported by Means [29], followed by a sharp decline in GFP expressing cells. The percentage of GFP positive cells drops from $77 \%$ in the absence of heparin to $12 \%$ at a heparin concentration of $1 \mathrm{mg} / \mathrm{ml}$. This result is also consistent with previously published findings and indicates that the assay is appropriate for measuring any change in viral entry. Also shown in Figure 10 is the neutralisation curve for HVS mORF51. A similar pattern is seen for the mutant virus; however, the decrease in GFP positive cells is less marked. The percentage of infected cells falls from $63 \%$ to $25 \%$, suggesting that although heparin does interfere with viral entry in HVS mOR51, this virus is less dependent on binding heparin than its "wild-type" counterpart. HVS viral entry involves several glycoproteins and some, including $\mathrm{gB}$, are also capable of binding heparin. Therefore, the only partial neutralisation observed for HVS mORF51 may be due to soluble heparin interacting with $\mathrm{gB}$. Moreover, the decreased neutralisation activity of soluble heparin on HVS mORF51 compared to HVS-GFP-BAC may be due to the removal of the heparan sulphate-binding motif from ORF51 of the virus, making it less sensitive to competitive inhibition.

\subsection{Somatostatin Does Not Neutralise HVS-GFP-BAC or HVS} mORF51. To further investigate the role of SSTRs in HVS mORF51 infectivity, the heparin neutralisation assay was modified to measure the effects of the 14-amino acid peptide somatostatin on virus entry. Again, concentrations from 0.01 to $1.0 \mathrm{mg} / \mathrm{ml}$ of soluble somatostatin were initially used; however, incubation with $1 \mathrm{mg} / \mathrm{ml}$ somatostatin proved to be toxic to the cells (Figures 11(a) and 11(b)). Therefore, the $1.0 \mathrm{mg} / \mathrm{ml}$ measurement was removed. Figure 10 plots the infection rate of HVS-GFP-BAC and HVS mORF51 against somatostatin concentration. Neither HVS-GFP-BAC nor HVS mORF51 appear to be neutralised by somatostatin. The infection rate at $0.25 \mathrm{mg} / \mathrm{ml}$ is similar to the rate when no somatostatin was added. The percentage GFP expression does decrease slightly when incubated with $0.5 \mathrm{mg} / \mathrm{ml}$ somatostatin, but this may be due to such a large amount of the peptide having an adverse effect on cell metabolism. Somatostatin naturally occurs in much lower concentrations in human plasma, typically around $50 \mathrm{pg} / \mathrm{ml}$. These results are consistent with the data obtained using the SSTR1-expressing cell lines and seem to imply that although the mutation has impaired the heparin-binding ability of mORF51, the protein does not bind somatostatin receptors. 


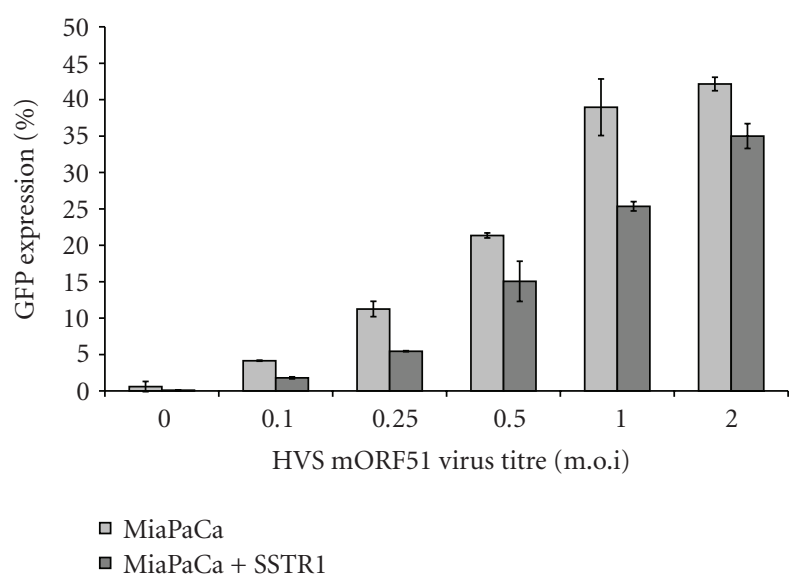

(a)

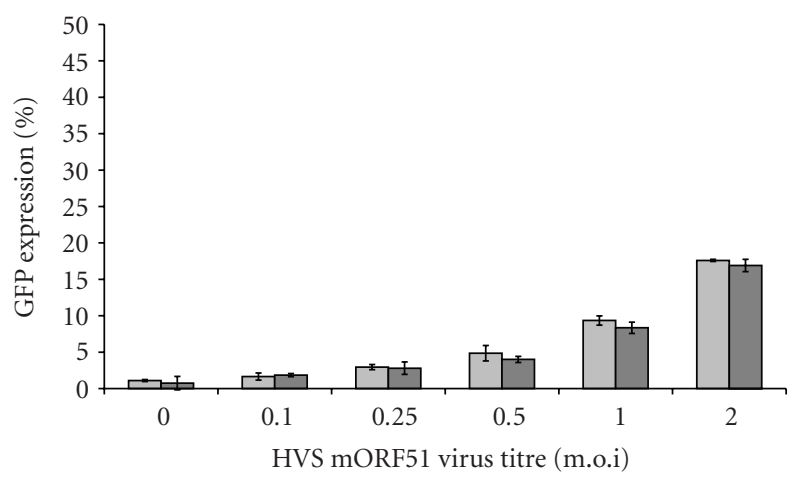

$\square$ Panc1

- Panc1 + SSTR1

FIGURE 9: Somatostatin receptor 1 is not required for HVS mORF51 cell entry. Two pancreatic cancer cell lines (MiaPaCa, and Panc1) were stably transfected with a construct expressing the SSTR1 gene. $48 \mathrm{~h}$ after infection with HVS mORF51, the cell lines expressing SSTR1 showed no increase in GFP expression as measured by flow cytometry, indicating that the recombinant virus does not interact with this receptor to enter the cell $(n=2)$.

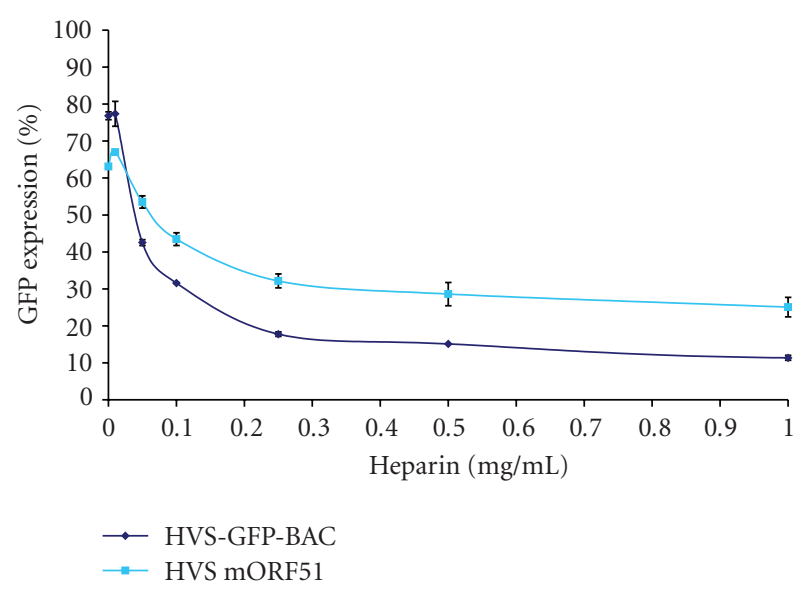

Figure 10: Soluble heparin blocks HVS-GFP-BAC entry in Huh7.5 cells and inhibits HVS mORF51 to a lesser extent. Cells were incubated with a range of concentrations of heparin in 5\% media for $1 \mathrm{~h}$ prior to infection with virus (also in 5\% media). $48 \mathrm{~h}$ after infection, cells were removed from their wells, and GFP fluorescence was measured by flow cytometry $(n=2)$. Concentrations of heparin over $0.05 \mathrm{mg} / \mathrm{ml}$ resulted in viral cell entry being inhibited with both viruses. However, the neutralisation effect is less severe with HVS mORF51, suggesting some attenuation of its heparinbinding capacity.

3.6. SSTR Antibody Fails to Neutralise HVS mORF51. The data so far suggests that HVS mORF51 has not gained the ability to bind SSTR expressing cells. However the toxic nature of high concentrations of somatostatin make interpretation of the neutralisation assay difficult. For this reason the assay was repeated, using an antibody raised against all 5 subtypes of somatostatin receptor. An antibody against mouse IgG was used as a negative control. The results of the neutralisation trial are shown in Figure 12. The level of GFP expression is fairly constant in all four assays, suggesting that increasing concentrations of SSTR antibody, as well as the antibody against IgG, fail to neutralise viral entry, irrespective of the mutated ORF51 protein. This result is consistent with the previous data and contradicts the hypothesis that somatostatin receptors are used for HVS mORF51 entry.

\section{Discussion}

Viruses are powerful gene therapy tools as they have evolved to efficiently enter their target cells and manipulate those cells into transcribing and translating their genetic material. To further exploit their gene therapy potential, techniques have been developed to retarget a virus to specifically enter or block entry to a particular cell type. Retargeting involves the modification of proteins on the surface of the virion and can be achieved by several means; molecules such as PEG can be covalently attached to the virus surface (although this is better described as detargeting) [44, 45]. Alternatively, specific viral proteins can be modified to enhance binding to target cells. Bispecific molecules such as bivalent ScFvs or antibodies covalently conjugated to ligands can alter binding $[46,47]$, or genetic mutation of viral proteins can provide a permanent change in tropism $[48,49]$.

Genetic modification affects all copies of the protein and would be preferable in conditionally replicating vectors to maintain targeting in the progeny virus. However, recombination is time consuming, and the mutation may impair virus production. Chemical modification is a more flexible system, allowing conjugation of multiple targeting ligands to one viral particle. The ratio of conjugated viral proteins can also be adjusted to suit the application, but production of bispecific peptides and/or antibodies is costly. Both strategies have been successfully applied in preclinical studies, suggesting that vector retargeting could have clinical 


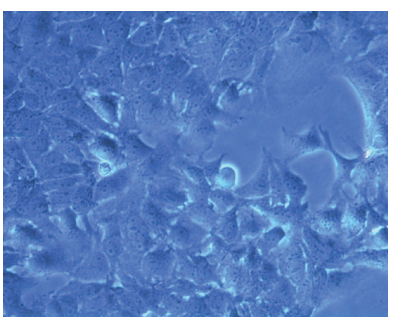

(a)

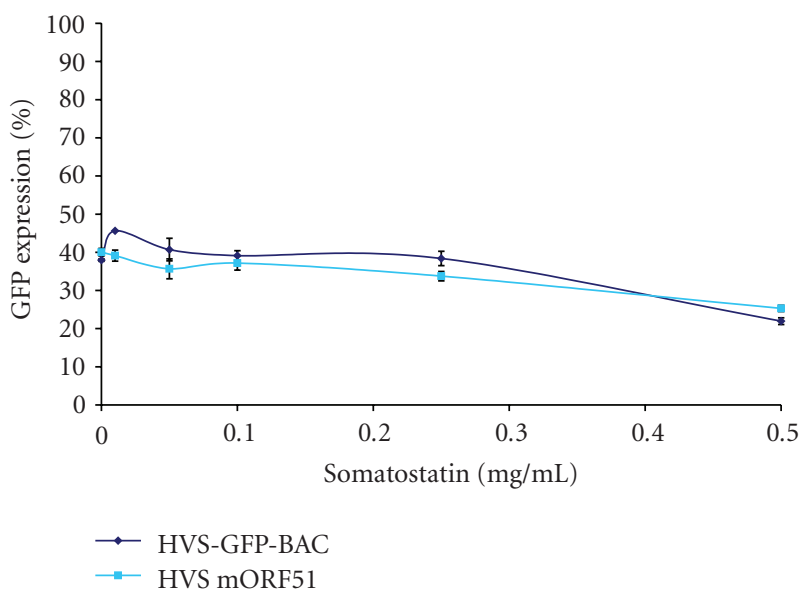

(c)

Figure 11: Somatostatin fails to neutralise HVS infection. The 14amino acid peptide somatostatin was incubated with Huh7.5 cells at a range of concentrations for $1 \mathrm{~h}$ prior to infection with either HVS-GFP-BAC or HVS mORF51. After $48 \mathrm{~h}$, GFP fluorescence was measured by flow cytometry $(n=2)$. Although cells incubated with up to $0.5 \mathrm{mg} / \mathrm{ml}$ somatostatin appeared healthy under the microscope (a), a concentration of $1 \mathrm{mg} / \mathrm{ml}$ was lethal (b). The graph (c) shows that both viruses exhibited negligible change in cell entry with increasing somatostatin concentration until the $0.5 \mathrm{mg} / \mathrm{ml}$ samples, where there is a reduced infection for both viruses. This may be due to the toxicity of the peptide rather than a true neutralisation effect.

benefit. We chose to use a genetic approach to ensure that all copies of the target protein contained the new binding motif.

We have mutated the HVS glycoprotein ORF51 in order to increase binding to hepatocellular carcinoma cells. The putative heparan sulphate-binding region of this protein was replaced with a motif designed to bind somatostatin receptors, which are overexpressed in this form of cancer. RecA-mediated recombination was used to introduce this specific mutation into the large HVS genome, as this powerful technique can mutate a single base in the context of the $170 \mathrm{~kb}$ virus. The desired mutation resulted in the exchange of just 17 amino acids, swapping residues 214228 of ORF51 (SKHTNKLKPFKHKLQ) with the sequence (RSPTGACRFWKTWCKRS). The underlined SSTR binding sequence was flanked by codons that contain restriction sites required for cloning and analysis.

The engineered HVS mORF51 virus was then used to infect a range of cancer cell lines to investigate any difference in tropism compared to wild type HVS. The mutant virus

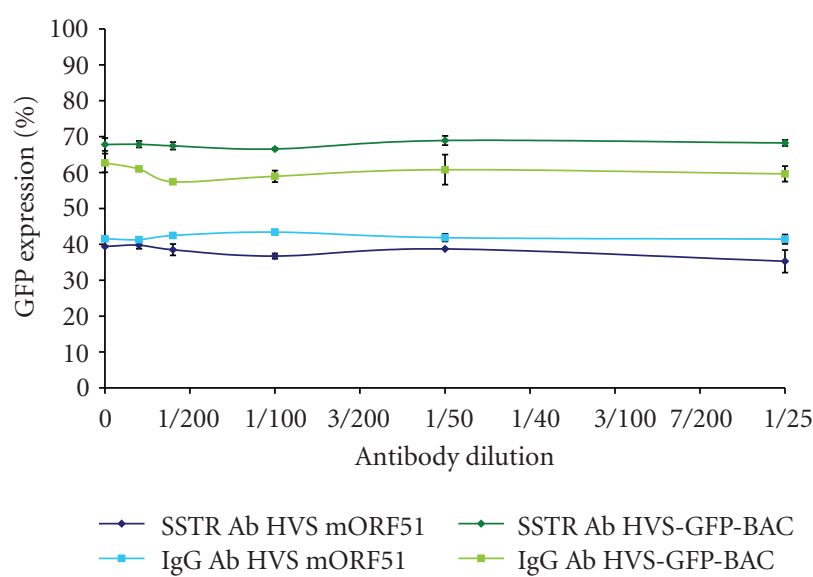

FIGURE 12: SSTR antibody fails to neutralise HVS mORF51 infection. Huh7.5 cells were incubated with antibody (SSTR or mouse IgG negative control) for $1 \mathrm{~h}$ prior to infection with HVSGFP-BAC or HVS mORF51. Samples were then measured for GFP expression using flow cytometry $48 \mathrm{~h}$ after infection $(n=2)$. Antibody concentration had no effect on either virus infection suggesting that SSTRs are not required for HVS mORF51 entry.

demonstrated a striking affinity for HCC cells while showing a reduced infectivity in other cell types, including the permissive owl monkey kidney line. Surprisingly, further investigation revealed that HVS mORF51 did not bind SSTRs, and that this change in tropism was due to another as yet unidentified mechanism. As the introduced mutation disrupts native ORF51 function, these results suggest that ORF51 is not required for HCC entry but does play a role in cell entry in a number of human cells.

ORF51 may act in a similar manner to EBV gp42, which is required for B-cell entry, but not for epithelial cell infection [50]. Other HVS glycoproteins such as gM and gN may facilitate initial binding of HCC cells or be involved in membrane fusion. To determine the essential glycoproteins required for entry in particular cell types, a series of mutant viruses with deleted glycoproteins could be constructed and characterised for infectivity. Although time consuming, this collection of viruses would provide a wealth of data regarding HVS infection and could aid in identification of corresponding cellular receptors for these glycoproteins. Alternatively, to locate possible HVS ligands on HCC cells, a cDNA library of HCC genes could be produced in OMK cells and virus-binding assays performed.

We cannot conclude that functional ORF51 is expressed in the HVS mORF51 virus therefore, the nature of the mutant protein can at present only be speculated. It is possible that the mutation caused such a dramatic change in structure that the protein cannot attain its native conformation, causing degradation. Alternatively, oligomerisation may have been affected, preventing ligand binding. Similarly, the SSTR binding region may be obscured, or in the wrong orientation to allow ligand interaction. The SSTR binding sequence itself contains an essential disulphide bridge between the flanking cysteine residues. Disruption of this bond would prevent the mORF51 protein-binding SSTRs on HCC cells. Investigation 
into the structural status of wild-type and mutant ORF51 could provide valuable data about its function. In addition, further studies with purified mORF51 protein could be carried out to assess its binding capabilities to SSTRs compared to wild-type ORF51. Expression would have to be performed in a eukaryotic system to ensure that the protein is appropriately glycosylated. Moreover, it would be interesting to determine the cell infectivity profile of a HVS $\triangle$ ORF51 virus, to assess if ORF51 is required for HCC cell entry, in contrast to other cell lines.

ORF51 shares genomic colinearity with EBV gp220/350, which binds complement receptor 2 (CR2) on host B cells [51]. This induces a signalling cascade which results in upregulated proliferation. It is possible that HVS ORF51 has a separate ligand in addition to heparan sulphate, and that interaction with this receptor induces beneficial changes to the intracellular environment for the virus. Many viruses have evolved to bind receptors that stimulate specific signalling pathways, which "prime" the cell for viral infection in this manner. Therefore, mutation of these viral proteins, and subsequent disruption of signalling may affect viral fitness and transgene expression by reducing the ability of the virus to control the cellular environment. This may contribute to the reduced infectivity of HVS mORF51. This phenomenon should be taken into account when designing retargeted vectors. One way to tackle this problem is to retain a wild-type copy of the mutant gene in the viral genome; however, this may mask the effects of the mutated protein.

HVS infection is a complex process, involving a variety of viral glycoproteins that act in concert to facilitate entry in HCC cells. Little research has been conducted into how these glycoproteins interact with cellular receptors and each other during this process. The data described here illustrates that ORF51 contributes to efficient cell entry in a number of human cell lines but does not appear to be involved in HCC cell entry. From these findings, it is clear that mutation of ORF51 has practical implications for HVS in gene therapy. Therefore, this research highlights the potential of a retargeted HVS-based vector in redirecting cell tropism.

\section{Acknowledgments}

The authors wish to thank Dr. Li Min of the Baylor College of Medicine, Houston, Texas for the kind donation of the pancreatic cancer cell lines stably expressing SSTR1. Thanks also go to Dr. Robert White of Imperial College London, for his guidance and expertise with the RecAmediated recombination system, and to Gareth Howell of the University of Leeds for his technical assistance with the FACS data. This work was supported by the BBSRC.

\section{References}

[1] B. Roizman, L. E. Carmichael, and F. Deinhardt, "Herpesviridae. Definition, provisional nomenclature, and taxonomy," Intervirology, vol. 16, no. 4, pp. 201-217, 1981.

[2] S. K. Geevarghese, D. A. Geller, H. A. De Haan et al., "Phase I/II study of oncolytic herpes simplex virus NV1020 in patients with extensively pretreated refractory colorectal cancer metastatic to the liver," Human Gene Therapy, vol. 21, no. 9, pp. 1119-1128, 2010.

[3] J. M. Markert, M. D. Medlock, S. D. Rabkin et al., "Conditionally replicating herpes simplex virus mutant G207 for the treatment of malignant glioma: results of a phase I trial," Gene Therapy, vol. 7, no. 10, pp. 867-874, 2000.

[4] N. N. Senzer, H. L. Kaufman, T. Amatruda et al., "Phase II clinical trial of a granulocyte-macrophage colony-stimulating factor-encoding, second-generation oncolytic herpesvirus in patients with unresectable metastatic melanoma," Journal of Clinical Oncology, vol. 27, no. 34, pp. 5763-5771, 2009.

[5] S. Macnab, R. White, J. Hiscox, and A. Whitehouse, "Production of an infectious Herpesvirus saimiri-based episomally maintained amplicon system," Journal of Biotechnology, vol. 134, no. 3-4, pp. 287-296, 2008.

[6] A. Whitehouse, "Herpesvirus saimiri: a potential gene delivery vector (review)," International Journal of Molecular Medicine, vol. 11, no. 2, pp. 139-148, 2003.

[7] S. Macnab and A. Whitehouse, "Progress and prospects: human artificial chromosomes," Gene Therapy, vol. 16, no. 10, pp. 1180-1188, 2009.

[8] J.-C. Albrecht, J. Nicholas, D. Biller et al., "Primary structure of the herpesvirus saimiri genome," Journal of Virology, vol. 66, no. 8, pp. 5047-5058, 1992.

[9] L. A. Falk, L. G. Wolfe, and F. Deinhardt, "Isolation of Herpesvirus saimiri from blood of squirrel monkeys (Saimiri sciureus)," Journal of the National Cancer Institute, vol. 48, no. 5, pp. 1499-1505, 1972.

[10] H. Fickenscher and B. Fleckenstein, "Herpesvirus saimiri," Philosophical Transactions of the Royal Society B: Biological Sciences, vol. 356, no. 1408, pp. 545-567, 2001.

[11] P. G. Smith, P. L. Coletta, A. F. Markham, and A. Whitehouse, "In vivo episomal maintenance of a herpesvirus saimiribased gene delivery vector," Gene Therapy, vol. 8, no. 23, pp. 17621769, 2001.

[12] B. Simmer, M. Alt, I. Buckreus, S. Berthold, B. Fleckenstein, and E. R. Platzer Grassmann, "Persistence of selectable herpesvirus saimiri in various human haematopoietic and epithelial cell lines," Journal of General Virology, vol. 72, no. 8, pp. 1953-1958, 1991.

[13] R. C. Desrosiers, J. Kamine, and A. Bakker, "Synthesis of bovine growth hormone in primates by using a herpesvirus vector," Molecular and Cellular Biology, vol. 5, no. 10, pp. 2796-2803, 1985.

[14] R. Grassmann and B. Fleckenstein, "Selectable recombinant herpesvirus saimiri is capable of persisting in a human T-cell line," Journal of Virology, vol. 63, no. 4, pp. 1818-1821, 1989.

[15] C. Wieser, D. Stumpf, C. Grillhösl et al., "Regulated and constitutive expression of anti-inflammatory cytokines by nontransforming herpesvirus saimiri vectors," Gene Therapy, vol. 12, no. 5, pp. 395-406, 2005.

[16] G. M. Doody, J. P. Leek, A. K. Bali, A. Ensser, A. F. Markham, and E. A. de Wynter, "Marker gene transfer into human haemopoietic cells using a herpesvirus Saimiri-based vector," Gene Therapy, vol. 12, no. 4, pp. 373-379, 2005.

[17] H. Shizuya, B. Birren, U.-J. Kim et al., "Cloning and stable maintenance of 300-kilobase-pair fragments of human DNA in Escherichia coli using an F-factor-based vector," Proceedings of the National Academy of Sciences of the United States of America, vol. 89, no. 18, pp. 8794-8797, 1992.

[18] C. M. Collins, M. M. Medveczky, T. Lund, and P. G. Medveczky, "The terminal repeats and latency-associated nuclear antigen of herpesvirus saimiri are essential for episomal 
persistence of the viral genome," Journal of General Virology, vol. 83, no. 9, pp. 2269-2278, 2002.

[19] M. A. Calderwood, K. T. Hall, D. A. Matthews, and A. Whitehouse, "The herpesvirus saimiri ORF73 gene product interacts with host-cell mitotic chromosomes and self-associates via its C terminus," Journal of General Virology, vol. 85, no. 1, pp. 147-153, 2004.

[20] K. T. Hall, M. S. Giles, D. J. Goodwin, M. A. Calderwood, A. F. Markham, and A. Whitehouse, "Characterization of the herpesvirus saimiri ORF73 gene product," Journal of General Virology, vol. 81, no. 11, pp. 2653-2658, 2000.

[21] M. Calderwood, R. E. White, R. A. Griffiths, and A. Whitehouse, "Open reading frame 73 is required for herpesvirus saimiri A11-S4 episomal persistence," Journal of General Virology, vol. 86, no. 10, pp. 2703-2708, 2005.

[22] R. Griffiths and A. Whitehouse, "Herpesvirus Saimiri episomal persistence is maintained via interaction between open reading frame 73 and the cellular chromosome-associated protein MeCP2," Journal of Virology, vol. 81, no. 8, pp. 40214032, 2007.

[23] R. Griffiths, S. M. Harrison, S. Macnab, and A. Whitehouse, "Mapping the minimal regions within the ORF73 protein required for herpesvirus saimiri episomal persistence," Journal of General Virology, vol. 89, no. 11, pp. 2843-2850, 2008.

[24] R. E. White, M. A. Calderwood, and A. Whitehouse, "Generation and precise modification of a herpesvirus saimiri bacterial artificial chromosome demonstrates that the terminal repeats are required for both virus production and episomal persistence," Journal of General Virology, vol. 84, no. 12, pp. 3393 3403, 2003.

[25] A. J. Stevenson, D. Clarke, D. M. Meredith, S. E. Kinsey, A. Whitehouse, and C. Bonifer, "Herpesvirus saimiri-based gene delivery vectors maintain heterologous expression throughout mouse embryonic stem cell differentiation in vitro," Gene Therapy, vol. 7, no. 6, pp. 464-471, 2000.

[26] R. A. Griffiths, J. R. Boyne, and A. Whitehouse, "Herpesvirus saimiri-based gene delivery vectors," Current Gene Therapy, vol. 6, no. 1, pp. 1-15, 2006.

[27] A. J. Stevenson, M. Cooper, J. C. Griffiths et al., "Assessment of Herpesvirus saimiri as a potential human gene therapy vector," Journal of Medical Virology, vol. 57, no. 3, pp. 269-277, 1999.

[28] P. G. Smith, S. A. Burchill, D. Brooke, P. L. Coletta, and A. Whitehouse, "Efficient infection and persistence of a herpesvirus saimiri-based gene delivery vector into human tumor xenografts and multicellular spheroid cultures," Cancer Gene Therapy, vol. 12, no. 3, pp. 248-256, 2005.

[29] R. E. Means, "Characterization of the Herpesvirus saimiri Orf51 protein,” Virology, vol. 326, no. 1, pp. 67-78, 2004.

[30] A. Birkmann, K. Mahr, A. Ensser et al., "Cell surface heparan sulfate is a receptor for human herpesvirus and interacts with envelope glycoprotein K8.1," Journal of Virology, vol. 75, no. 23, pp. 11583-11593, 2001.

[31] R. E. Luna, F. Zhou, A. Baghian et al., "Kaposi's sarcomaassociated herpesvirus glycoprotein K8.1 is dispensable for virus entry," Journal of Virology, vol. 78, no. 12, pp. 6389-6398, 2004.

[32] P. G. Smith, F. Oakley, M. Fernandez, D. A. Mann, N. R. Lemoine, and A. Whitehouse, "Herpesvirus saimiri-based vector biodistribution using noninvasive optical imaging," Gene Therapy, vol. 12, no. 19, pp. 1465-1476, 2005.

[33] J. Bruix, L. Boix, M. Sala, and J. M. Llovet, "Focus on hepatocellular carcinoma," Cancer Cell, vol. 5, no. 3, pp. 215219, 2004.
[34] L. Lévy, C. A. Renard, Y. Wei, and M. A. Buendia, "Genetic alterations and oncogenic pathways in hepatocellular carcinoma," Annals of the New York Academy of Sciences, vol. 963, pp. 21-36, 2002.

[35] J. Bruix, A. J. Hessheimer, A. Forner, L. Boix, R. Vilana, and J. M. Llovet, "New aspects of diagnosis and therapy of hepatocellular carcinoma," Oncogene, vol. 25, no. 27, pp. 3848-3856, 2006.

[36] M. Bläker, M. Schmitz, A. Gocht et al., "Differential expression of somatostatin receptor subtypes in hepatocellular carcinomas," Journal of Hepatology, vol. 41, no. 1, pp. 112-118, 2004.

[37] H. Reynaert, K. Rombouts, A. Vandermonde et al., "Expression of somatostatin receptors in normal and cirrhotic human liver and in hepatocellular carcinoma," Gut, vol. 53, no. 8, pp. 1180-1189, 2004.

[38] Y. Zou, X. Xiao, Y. Li, and T. Zhou, "Somatostatin analogues inhibit cancer cell proliferation in an SSTR2-dependent manner via both cytostatic and cytotoxic pathways," Oncology Reports, vol. 21, no. 2, pp. 379-386, 2009.

[39] M. Lalioti and J. Heath, "A new method for generating point mutations in bacterial artificial chromosomes by homologous recombination in Escherichia coli," Nucleic acids research, vol. 29, no. 3, p. E14, 2001.

[40] R. M. Wright, H. Gram, A. Vattay, S. Byrne, P. Lake, and D. Dottavio, "Binding epitope of somatostatin defined by phagedisplayed peptide libraries," Bio/Technology, vol. 13, no. 2, pp. 165-169, 1995.

[41] Y. C. Patel, "Somatostatin and its receptor family," Frontiers in Neuroendocrinology, vol. 20, no. 3, pp. 157-198, 1999.

[42] W. J. Rossowski and D. H. Coy, "Specific inhibition of rat pancreatic insulin or glucagon release by receptor-selective somatostatin analogs," Biochemical and Biophysical Research Communications, vol. 205, no. 1, pp. 341-346, 1994.

[43] M. Li, X. Wang, W. Li et al., "Somatostatin receptor-1 induces cell cycle arrest and inhibits tumor growth in pancreatic cancer," Cancer Science, vol. 99, no. 11, pp. 2218-2223, 2008.

[44] C. R. O’Riordan, A. Lachapelle, C. Delgado et al., "PEGylation of adenovirus with retention of infectivity and protection from neutralizing antibody in vitro and in vivo," Human Gene Therapy, vol. 10, no. 8, pp. 1349-1358, 1999.

[45] A. Danielsson, G. Elgue, B. M. Nilsson et al., "An ex vivo loop system models the toxicity and efficacy of PEGylated and unmodified adenovirus serotype 5 in whole human blood," Gene Therapy, vol. 17, no. 6, pp. 752-762, 2010.

[46] E. J. Roy, B. K. Cho, L. A. Rund, T. A. Patrick, and D. M. Kranz, "Targeting T cells against brain tumors with a bispecific ligand-antibody conjugate," International Journal of Cancer, vol. 76, no. 5, pp. 761-766, 1998.

[47] S.-K. Yoon, L. Mohr, C. R. O’Riordan, A. Lachapelle, D. Armentano, and J. R. Wands, "Targeting a recombinant adenovirus vector to HCC cells using a bifunctional Fabantibody conjugate," Biochemical and Biophysical Research Communications, vol. 272, no. 2, pp. 497-504, 2000.

[48] J. T. Douglas and D. T. Curiel, "Strategies to accomplish targeted gene delivery to muscle cells employing tropismmodified adenoviral vectors," Neuromuscular Disorders, vol. 7, no. 5, pp. 284-298, 1997.

[49] J. Conner, L. Braidwood, and S. M. Brown, "A strategy for systemic delivery of the oncolytic herpes virus HSV1716: redirected tropism by antibody-binding sites incorporated on the virion surface as a glycoprotein D fusion protein," Gene Therapy, vol. 15, no. 24, pp. 1579-1592, 2008. 
[50] P. L. Shaw, A. N. Kirschner, T. S. Jardetzky, and R. Longnecker, "Characteristics of Epstein-Barr virus envelope protein gp42," Virus Genes, vol. 40, no. 3, pp. 307-319, 2010.

[51] J. D. Fingeroth, J. J. Weis, and T. F. Tedder, "Epstein-Barr virus receptor of human B lymphocytes is the C3d receptor CR2," Proceedings of the National Academy of Sciences of the United States of America, vol. 81, no. 14 I, pp. 4510-4514, 1984. 

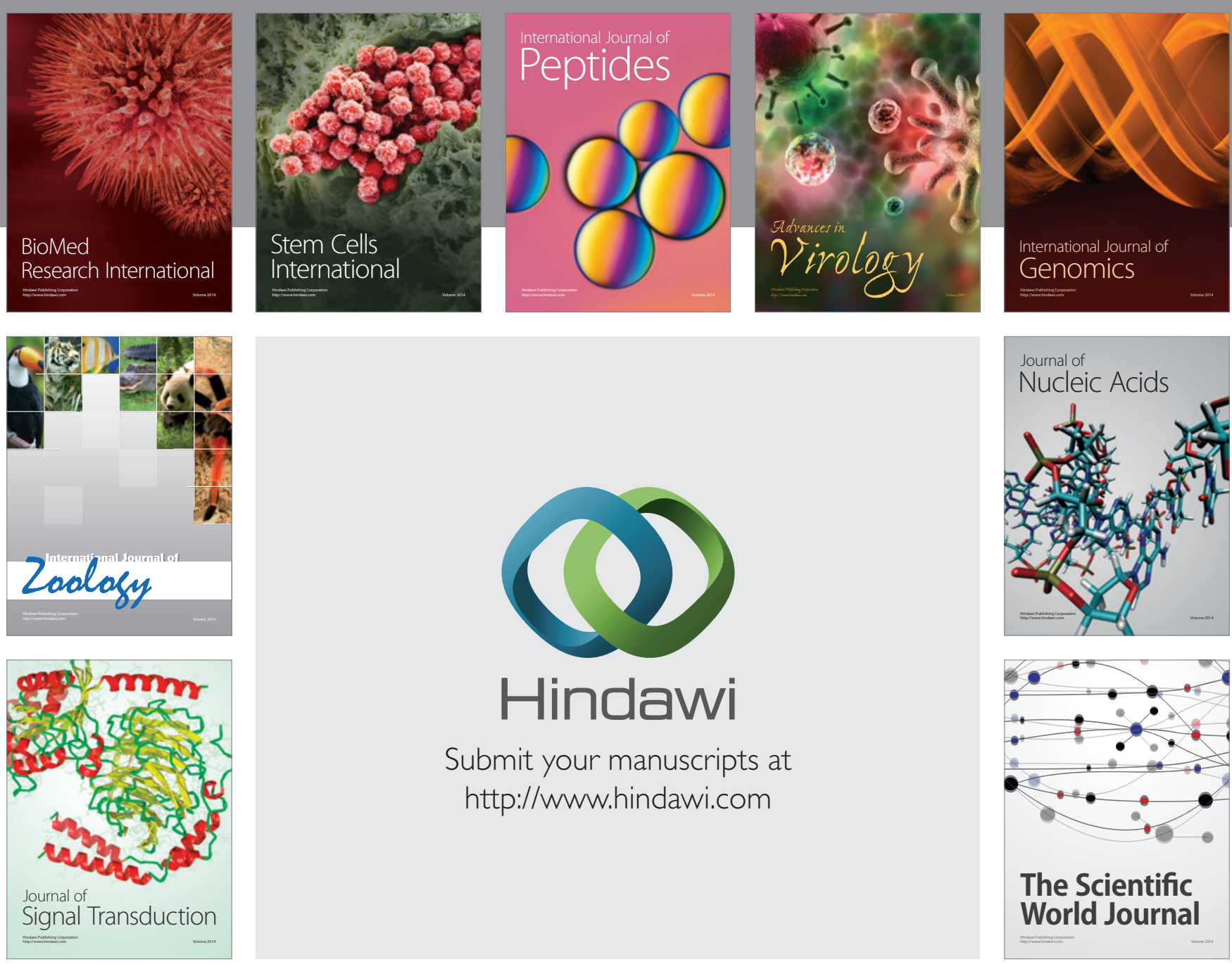

Submit your manuscripts at

http://www.hindawi.com
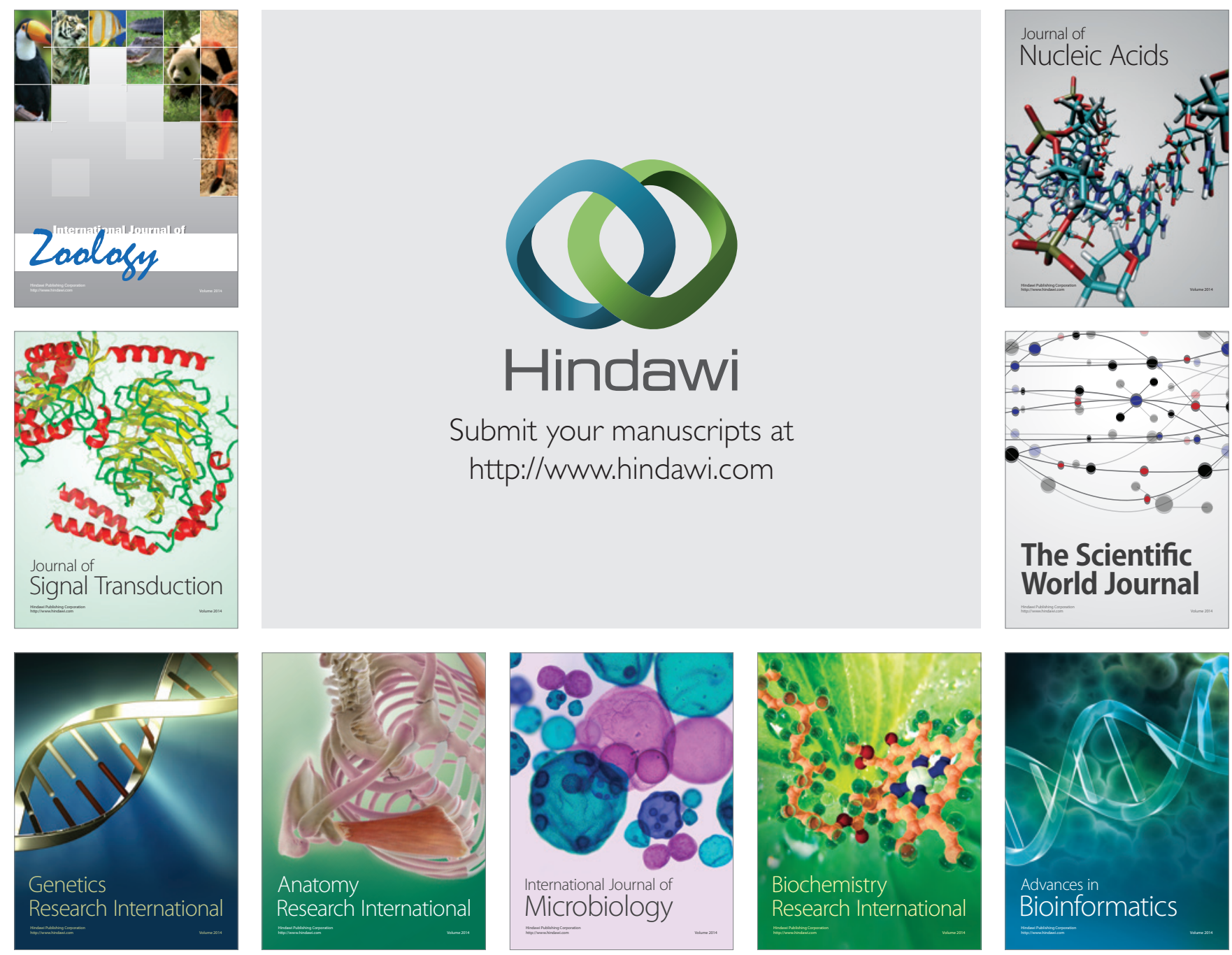

The Scientific World Journal
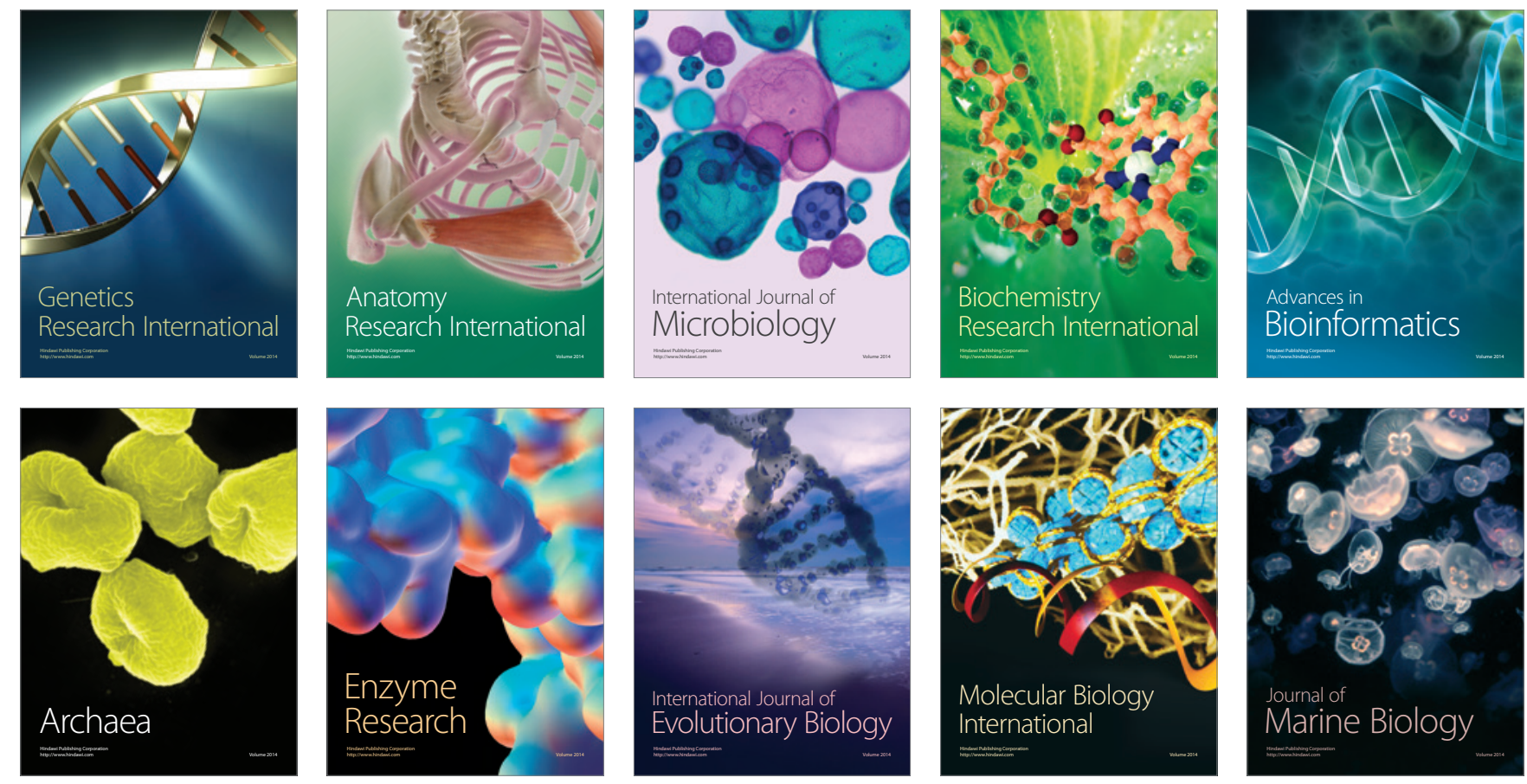